\title{
ERP Configuration: Does Situation Awareness Impact Team Performance?
}

\author{
Lionel Robert, Ph.D. \\ University of Arkansas \\ Walton College of Business \\ Information Systems Department \\ 1robert@walton.uark.edu
}

\author{
Alexander McLeod, Ph.D. \\ University of Nevada, Reno \\ Accounting \& Information Systems \\ amcleod@unr.edu
}

\author{
Ashley R. Davis, Ph.D. \\ San Jose State University \\ Accounting \& Finance Department \\ ashley.r.davis@sjsu.edu
}

\begin{abstract}
Globalization, tougher competition and increasing customer expectations have led many organizations to adopt enterprise resource planning systems (ERP). However, organizations are beginning to realize the real impacts of ERP systems can be less than expected and that there is a need to better utilize ERP systems. This has led to greater focus on improved configuration and implementation. An important part of implementation is the configuration process carried out by teams. In this study, we present our research model and examine performance in ERP configuration teams. The research model posits that Team Situation Awareness (TSA) affects the performance of ERP configuration teams and that process conflict, deadlines and sharing common languages and codes will impact TSA. We then empirically tested the model in a quasifield study involving 26 ERP/SAP student configurations teams. The results support our research model and offer insight into configuration team performance. Implications for theory and practice are discussed.
\end{abstract}

\section{Introduction}

Globalization, tougher competition, and increasing customer expectations have increased the importance of real time information to organizations $[2,27]$. Real time information can only be achieved through complete integration of information systems across organizations. This had lead to many companies adopting enterprise resource planning systems. An ERP system can be defined as a companywide information system that has the potential to integrate all business functions such as: human resources, accounting, sales, manufacturing, distribution and supply change management [2].

Organizations have discovered that the use of ERP systems can reduce operating costs and augment the ability to respond quickly to changing market conditions. For example, IBM Storage Systems was able to re-price all products in 5 minutes rather than the previous time of 5 days. It also reduced their shipment time for replacement parts from 22 days to 3 days [2].

Achieving these types of benefits with an ERP system is not without risk. ERP implementations often require employees to adopt both a new information system and new business processes. Both of these changes can lead to implementation failure. Failed ERP implementations are legendary and include organizations such as Boeing, Siemens, and Panasonic [27]. These failures are extremely costly. For example, Unisource Worldwide wrote off 168 million in cost to abandon their ERP implementation [2].

Many companies have avoided the major problems associated with ERP implementations that haunted organizations a decade ago. Nonetheless, many organizations are beginning to realize that the real impacts of ERP systems are less than expected and that there is a need to better utilize ERP systems to achieve the desired benefits through better management of their resources [31]. This has drawn attention to finding ways to improve ERP implementations. However, much of the ERP implementation research has focused only on organizational level variables despite the fact that a configuration team handles the initial configuration of an ERP system. We find that little research has been done to understand how to improve the effectiveness of these configuration teams.

ERP configuration is a process whereby team members set up an ERP system to match the current or proposed organizational structure and business processes. The quality of the implementation is determined in part, by how well the ERP system is configured to match the current or proposed organization structure and business processes. This in turn determines whether managers will be able to utilize ERP systems fully to achieve their desired post configuration benefits. 
We believe that team situation awareness can help explain performance in ERP configuration teams. Team situation awareness can be defined as a 'shared understanding' of the current circumstances [30]. Team situation awareness has been found to play a significant role in the performance of military teams, air traffic controllers, and maintenance operations [8, 26]. Recently, Espinosa, Slaughter, Kraut, and Herbsleb [9] suggested that team situation awareness should influence software team performance. Thus, the use of TSA in measuring improvements in an ERP configuration project might be a valuable addition to the research in this area.

Despite the apparent importance of team situation awareness we know very little about which team behaviors impact team situation awareness [30, 32]. In this paper, we attempt to identify three factors we believe will affect the development of TSA. Some of the value in this research is in the testing of the TSA theory and therefore we test the impact of TSA on the performance of ERP configuration teams. We hope that this paper will contribute to our understanding by demonstrating that TSA impacts performance in ERP configuration teams, providing greater insight into how to increase performance in configuration teams implementing ERP systems.

\section{Theoretical review and hypotheses development}

Situation awareness has received a great deal of attention from researchers studying complex collaborative environments such as aviation, fire fighting and emergency medical service teams [34]. Within the context of teams configuring, implementing, and using an enterprise system, the factors affecting team situational awareness become of great consequence $[1,12,16,23,24,26]$.

ERP system configuration teams are similar to other collaborative groups in that they must pursue multiple simultaneous goals making situational awareness essential. This multi-goal setting is compounded by highly stressful processes holding severe negative consequences associated with poor team performance $[15,25]$. As a result, we believe that TSA is an important predicator of performance in ERP configuration teams.

\subsection{Team situational awareness and team performance}

TSA can increase coordination by enabling teams to understand their current situation and interpret the actions of other team members [28]. This, in turn, allows them to predict the behavior of their teammates. As a result, teams understand when and what needs to be done as well as how it should be done. This provides at least two performance benefits. First, teams are better able to coordinate their efforts without a need to overtly communicate [3]. Second, TSA allows teams to map out and predict the outcomes of a course of action prior to taking that action [19].

TSA also provides the contextual background that can help to facilitate the exchange of meaningful communication to integrate knowledge within teams $[18,22]$. Therefore, teams high in TSA understand what information has to be exchanged and when to exchange it. As a result, when teams are high in TSA their communication process is much more efficient and effective. These teams have the ability to rapidly process information into meaningful structures allowing teams to adapt to dynamically changing environments. As a result, we would expect TSA to positively affect performance in ERP configurations teams.

H1: Team Situation Awareness will positively affect team performance in ERP configuration teams.

\subsection{Process conflict and team situational awareness}

Process conflict refers to team member disagreement over how the team should carry out the task [14]. Process conflict occurs when team members have different understandings of project goals and methodologies on how to complete project deliverables [15]. Exchanging information and recognizing differences in individual situational awareness are important to developing TSA. Project conflict can lead to a complete breakdown of team communications, which reduces both information exchange and the ability to recognize differences in individual situational awareness. Process conflict can lead to team members not understanding what is expected of them to complete the project goal, which decreases the ability of team members to understand the environment around them. Process conflict can also be a distraction by having team members focus their attention on internal issues related to process 
conflict rather than the external environment, which allows them to achieve TSA.

H2: Process conflict will negatively affect team situational awareness.

\subsection{Deadlines and Team Situational Awareness}

Team situation awareness requires an understanding and evaluation of the factors that might impact the project [29]. Behavior based control or outcome based control are common performance evaluation strategies [6]. One such behavioral control is team deadlines. Team deadlines attempt to structure the work process into clearly defined and scheduled milestones. These deadlines help provide feedback to the team that can help them assess certain situations. As a result, theory would suggest that deadlines, which provide the current status of progress towards the goals of the project, would positively impact team situational awareness.

H3: Team deadlines will positively affect team situational awareness.

\subsection{Shared languages and codes in team situational awareness}

Just as a lack of communication between team members may affect situational awareness, so too a lack of a common language can cause difficulties. When members share languages and mental models of the process environment their ability to achieve a common perception of situation awareness improves [20]. Without a common set of definitions or codes accompanied by a shared language, the possibility of forming an incorrect perception of a situation increases [7]. Of particular interest here is the role of shared languages and codes in facilitating situational awareness to improve team performance when working with an ERP system [21]. Similar to Kaber and Endsley [15], we believe that shared languages can lead to heightened performance through improved communication and coordination. Such languages and models can provide teams with a firm knowledge of who has the needed information for a particular problem.

A lack of understanding of individual roles and responsibilities may facilitate poor team communication and these difficulties can arise either within or between crews of workers in coordinating process tasks and information. Team process behaviors showing an integration and understanding of roles, responsibilities and information, require detailed information flow between members [17]. Some researchers [11, 33] have suggested one ongoing problem with situational analysis is the lack of a common set of terms or shared language. We support this notion and believe that shared languages and codes may affect team situational awareness and ultimately performance. Therefore, our fourth hypothesis is directed towards the effect of shared languages and codes on team situational awareness.

H4: Shared languages and codes will positively affect team situational awareness.

We fashioned our model to represent the relationships between project performance, team situational awareness, team deadlines, process conflict and shared languages. Figure 1 shows the relationships between these constructs.

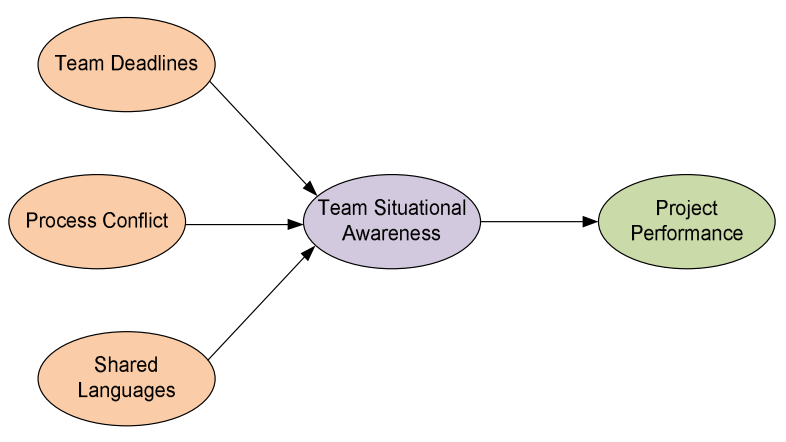

Figure 1 - Team situational awareness research model

\section{Research method}

To test the proposed research model we used a survey method and collected data to test our hypotheses. We choose to use Robust Path Analysis found in WarpPLS 1.0, because of its ability to analyze and report on both linear and curvilinear relationships. We viewed this to be superior to other PLS packages, which only provide linear results.

\subsection{Sample}

Data was collected from 110 individuals comprising $26 \mathrm{ERP} / \mathrm{SAP}$ student configuration teams. We also obtained demographic data concerning team tenure, team size and team grade point average. In addition gender, age, student status and degree type were included. Twenty six percent of the students were females with an average age of 24.5 years. Six 
teams were graduate teams consisting of both part time and full time students as well as non-degree seeking students who had completed an undergraduate degree. Ninety five percent of the 20 undergraduate teams consisted of seniors, while the remaining five consisted of both graduate and junior level students. Students at both levels, graduate and undergraduate took the ERP/SAP configuration course as part of a three course certificate program offered through the SAP University Alliance at a public university. The program is administered through a joint private and public venture involving several Fortunate 500 companies.

The ERP/SAP project required the configuration teams to build a company using the Financial Accounting (FI), Materials Management (MM), and Sales and Distribution (SD) modules of SAP. In addition, teams had to map the organizational structure, create master data, and focused on implementing the business processes in the SAP ERP environment. The project lasted for half of the semester. The SAP University Alliance provided the course curriculum and materials.

\subsection{Measurement model}

The survey was comprised of items developed in previous literature where possible. Items related to deadlines came from Crisp [5]. Shared language and codes questions were taken from Collins and Smith [4]. The process conflict items came from Jehn, [13, 14]. Project performance was measured by the team's score on the ERP configuration project. The items for situation awareness were new but were derived from prior literature (see 16, 31, 32 34). Appendix A provides the survey used in this study.

\subsection{Data analysis}

The composite reliability of situation awareness, process conflict, deadlines and shared language and codes were $.97, .89, .94$ and .98 respectively. All composite reliabilities exceed .7, providing acceptable reliability [10]. Convergent validity and discriminant validity is evaluated by the square root of the average variance extracted (AVE). The AVE should be greater than .5 to achieve convergent validity and be higher than the correlation among the other latent variables. All constructs meet or exceed the standards for convergent and discriminant validity. Table 1 details the AVE, composite reliability and Cronbach's alpha four our constructs. Appendix A provides factor loadings and cross loadings.
Table 1 - Average Variance Extracted, Composite Reliability and Cronbach's Alpha

\begin{tabular}{|l|c|c|c|}
\hline & AVE & $\rho \mathrm{c}$ & CA \\
\hline Process Conflict & .96 & .97 & .97 \\
\hline Shared Language & .96 & .98 & .97 \\
\hline Situational Awareness & .94 & .97 & .96 \\
\hline Team Deadlines & .91 & .94 & .89 \\
\hline
\end{tabular}

The path values ( $\beta$ ), p values and $R^{2}$ for the test of the hypotheses are shown in figure 2 .

\section{Results}

We analyzed the results for the four hypotheses. Hypothesis 1 stated that TSA should positively affect performance in ERP configuration teams. H1 was supported, TSA positively and significantly affected ERP configuration team performance $(\beta=.41 ; \mathrm{p}<$ $.01)$. Team situation awareness explained $37 \%$ of the variance in ERP configuration team performance. Hypothesis 2 stated that process conflict would negatively affect situational awareness. H2 was supported; process conflict negatively and significantly affected TSA $(\beta=-.23 ; \mathrm{p}<.05)$. Hypothesis 3 stated that team deadlines would

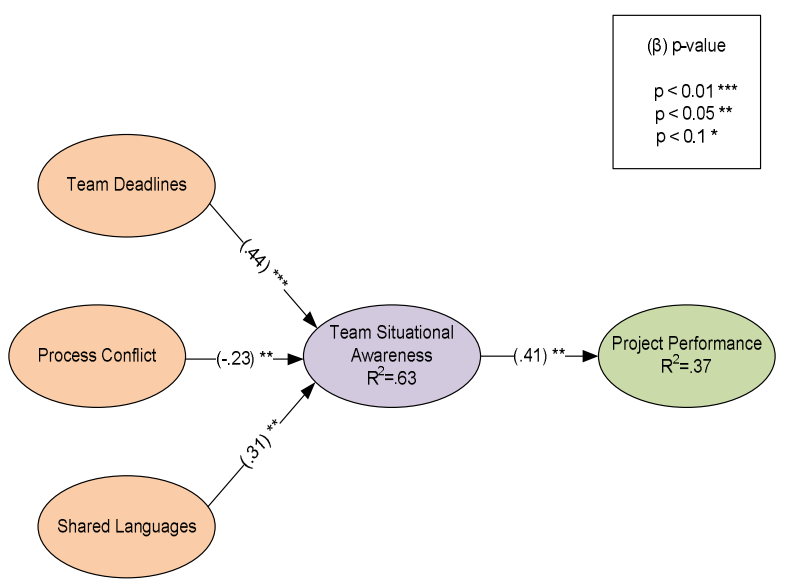

Figure 2 - Results

positively affect team situational awareness. H3 was supported, team deadlines significantly and positively affected TSA $(\beta=.44 ; \mathrm{p}<.01)$. Hypothesis 4 stated that shared common languages and codes would positively affect TSA. H4 was supported, shared common languages and codes significantly and positively affected TSA $(\beta=.31 ; \mathrm{p}<.05)$. Process conflict, deadlines, and shared language and codes collectively explained $64 \%$ of the variance in TSA. 
Appendix B provides the correlation matrix for this analysis and table 2 reports the path value and corresponding $\mathrm{p}$ value for the hypothesized relationships between these constructs.

Table 2 - Summary of Results

\begin{tabular}{|l|c|c|}
\hline & $\beta$ & $\begin{array}{c}p \\
\text { value }\end{array}$ \\
\hline H1 TSA $\rightarrow$ Performance & .41 & .02 \\
\hline H2 Process Conflict $\rightarrow$ TSA & -.23 & .04 \\
\hline H3 Team Deadlines $\rightarrow$ TSA & .44 & .01 \\
\hline H4 Shared Language $\rightarrow$ TSA & .31 & .02 \\
\hline
\end{tabular}

\section{Limitations}

Like all research, our research had limitations. One of these was the use of student teams as surrogates for professionals. Configuration tasks performed by students in a class can be less complex than those performed by professionals. Professional configuration teams may be impacted by more complex issues than student teams. In addition, student teams can suffer from a lack of motivation to do well. However, these students were probably motivated to do well to receive their ERP certificate. Another limitation is the number of teams analyzed. More teams would have made results more reliable, however we believe that an analysis of 26 configuration teams provides value in understanding TSA. Future studies are needed to understand the link between ERP utilization and improved implementation processes. It should be noted that the sample size and new items (TSA) reflect the early stages of a more complete research project.

\section{Discussion}

Despite the importance of configuration to the overall implementation process and subsequent use of ERP systems, little is known about how to increase the performance of the teams that conduct ERP configuration. This study had two objectives. First, we wanted to identify TSA as an important predictor of performance in ERP configuration teams. Second, we wanted to identify several important predictors of TSA. To accomplish this we conducted a quasi-field study examining the performance of ERP/SAP configuration teams. We proposed a theoretical research model to explain the performance of ERP configurations through TSA. We empirically tested this model and our findings generally supported our research model.

We believe this makes two contributions. One, we identify an important and much understudied part of the overall ERP implementation process, ERP configuration. We then highlight how TSA could affect the performance of ERP configuration teams. In doing so, we provide insight for both academics and practitioners on how to improve the ERP implementation process. Two, we contribute to the TSA literature by proposing new constructs that impact TSA. This provides both academics and practitioners with new insights into how to increase TSA.

\section{Conclusion}

Organizations are increasingly adapting and using ERP systems to manage their resources. Helping these organizations improve their adaption of these systems is the first step to ensure that those employing ERP systems receive their full benefit. Team situation awareness has been shown to increase the performance of military and software teams. Yet very little is known about which team behaviors or attitudes impact TSA [30]. This study links ERP configuration performance to TSA and sheds light on new potential predicators of TSA.

\section{References}

[1] M. Al-Mashari, A. Al-Mudimigh, and M. Zairi, "Enterprise resource planning: A taxonomy of critical factors," European Journal of Operational Research, vol. 146, pp. 352-364, 2003.

[2] P. Bingi, M. K. Sharma, and J. K. Godla, "Critical Issues Affecting an ERP Implementation," Information Systems Management, vol. 16, pp. 7-14, 1999.

[3] J. A. Cannon-Bowers, E. Salas, and S. Converse, "Shared mental models in expert team decision making," Environmental Effects of Cognitive Abilities, pp. 221-245, 2001 .

[4] C. J. Collins and K. G. Smith, "Knowledge exchange and combination: The role of human resource practices in the performance of high-technology firms," Academy of Management Journal, vol. 49, pp. 544-560, 2006.

[5] C. B. Crisp, "Control enactment in global virtual teams." vol. Ph.D. Austin: University of Texas, 2003.

[6] K. M. Eisenhardt, "Control: Organizational and economic approaches," Management Science, vol. 31, pp. 134-149, 1985.

[7] M. R. Endsley and D. J. Garland, Situation awareness: analysis and measurement: CRC Press, 2000. 
[8] M. R. Endsley and M. M. Robertson, "Situation awareness in aircraft maintenance teams," International Journal of Industrial Ergonomics, vol. 26, pp. 301-325, 2000 .

[9] J. A. Espinosa, S. A. Slaughter, R. E. Kraut, and J. D. Herbsleb, "Team knowledge and coordination in geographically distributed software development," Journal of Management Information Systems, vol. 24, pp. 135-169, 2007.

[10] C. Fornell and D. F. Larcker, "Evaluating structural equation models with unobservable variables and measurement error," Journal of marketing research, vol. 18, pp. 39-50, 1981.

[11] M. Gravelle, "Chief scientist report special: Technical inquiry on situational awareness," in CSERIAC Gateway, 1991.

[12] Z. Huang and P. Palvia, "ERP implementation issues in advanced and developing countries," Business Process Management Journal, vol. 7, pp. 276-284, 2001.

[13] K. A. Jehn, "A Quantitative Analysis of Conflict Types and Dimensions in Organizational Groups," Administrative Science Quarterly, vol. 42, 1997.

[14] K. A. Jehn, G. B. Northcraft, and M. A. Neale, "Why differences make a difference: A field study of diversity, conflict, and performance in workgroups," Administrative Science Quarterly, vol. 44, 1999.

[15] D. B. Kaber and M. R. Endsley, "Team situation awareness for process control safety and performance," Process Safety Progress, vol. 17, pp. 43-48, 1998.

[16] T. J. Kiely, "Managing change: why reengineering projects fail," Harvard Business Review, vol. 73, p. 15, 1995.

[17] L. J. Kirsch, "The management of complex tasks in organizations: Controlling the systems development process," Organization Science, vol. 7, pp. 1-21, 1996.

[18] J. Li and D. C. Hambrick, "Factional Groups: A New Vantage on Demographic Faultlines, Conflict, and Disintegration in Work Teams," The Academy of Management Journal, vol. 48, pp. 794-813, 2005.

[19] J. E. Mathieu, T. S. Heffner, G. F. Goodwin, E. Salas, and J. A. Cannon-Bowers, "The influence of shared mental models on team process and performance," Journal of Applied Psychology, vol. 85, pp. 273-283, 2000.

[20] K. L. Mosier and T. R. Chidester, "Situation assessment and situation awareness in a team setting," Designing for everyone, pp. 798-800, 1991.
[21] E. Muniz, R. J. Stout, and E. Salas, "Communication as an indicator of team situation awareness," in 42nd Annual Meeting of the Southeastern Psychological Association Norfolk, VA, 1996.

[22] J. Nahapiet and S. Ghoshal, "Social capital, intellectual capital, and the organizational advantage," The Academy of Management Review, vol. 23, pp. 242-266, 1998.

[23] E. W. T. Ngai, C. C. H. Law, and F. K. T. Wat, "Examining the critical success factors in the adoption of enterprise resource planning," Computers in Industry, vol. 59, pp. 548-564, 2008.

[24] M. R. Osman, R. M. Yusuff, S. H. Tang, and S. M. Jafari, "ERP systems implementation in Malaysia: the importance of critical success factors," International Journal of Engineering and Technology, vol. 3, pp. 125$131,2006$.

[25] G. Piccoli, A. Powell, and B. Ives, "Virtual teams: team control structure, work processes, and team effectiveness," Information Technology \& People, vol. 17, pp. 359-379, 2004.

[26] M. D. Proctor, M. Panko, and S. J. Donovan, "Considerations for training team situation awareness and task performance through PC-gamer simulated multiship helicopter operations," The International Journal of Aviation Psychology, vol. 14, pp. 191-205, 2004.

[27] D. Robey, J. W. Ross, and M. C. Boudreau, "Learning to implement enterprise systems: an exploratory study of the dialectics of change," Journal of Management Information Systems, vol. 19, pp. 17-46, 2002.

[28] E. M. Roth, J. Multer, and T. Raslear, "Shared situation awareness as a contributor to high reliability performance in railroad operations," Organization Studies, vol. 27 , p. 967,2006

[29] E. Salas, C. Prince, D. Baker, and L. Shrestha, "Situation awareness in team performance: Implications for measurement and training," Human Factors, vol. 37, pp. 123-136, 1995.

[30] P. M. Salmon, N. A. Stanton, G. H. Walker, C. Baber, D. P. Jenkins, R. McMaster, and M. S. Young, "What really is going on," Review of situation awareness models for individuals and teams. Theoretical Issues in Ergonomics Science, vol. 9, pp. 297-323, 2008.

[31] P. Samaranayake, "Business process integration, automation, and optimization in ERP," Business Process Management Journal, vol. 15, pp. 504-526, 2009. 
[32] N. Sarter and D. Woods, "Situation awareness: A critical but ill defined phenomenon," International Journal of Aviation Psychology, vol. 1, pp. 45-57, 1991.

[33] D. Sonnenwald, H. Soderholm, J. Manning, B. Cairns, G. Welch, and H. Fuchs, "Exploring the potential of video technologies for collaboration in emergency medical care," Journal of the American Society for Information Science and Technology, vol. 59, pp. 2320-2334, 2008.
[34] N. Stanton and P. Salmon, "Distributed situation awareness: Advances in theory, measurement and application to team work," in School of Engineering and Design. vol. Ph.D. Theses West London: Brunel University, 2008.

\section{Appendix A - Survey and Factor Loadings}

\begin{tabular}{|l|c|c|c|c|}
\hline & Situation & & & $\begin{array}{c}\text { Shared } \\
\text { Language } \\
\text { and } \\
\text { Codes }\end{array}$ \\
\hline We have a good understanding of our project status. & $\mathbf{0 . 9 3}$ & -0.61 & 0.61 & 0.47 \\
\hline We know what needs to be done to complete this project. & $\mathbf{0 . 9 3}$ & -0.54 & 0.63 & 0.73 \\
\hline $\begin{array}{l}\text { We know what has been done toward the completion of our } \\
\text { project. }\end{array}$ & $\mathbf{0 . 9 4}$ & -0.51 & 0.69 & 0.65 \\
\hline We know what is left to be done to complete this project. & $\mathbf{0 . 9 7}$ & -0.62 & 0.67 & 0.53 \\
\hline $\begin{array}{l}\text { How often do members of your team disagree about who } \\
\text { should do what? }\end{array}$ & -0.55 & $\mathbf{0 . 9 8}$ & -0.47 & -0.49 \\
\hline $\begin{array}{l}\text { How often was there conflict among your team members } \\
\text { about the activities carried out during the team discussion? }\end{array}$ & -0.57 & $\mathbf{0 . 9 6}$ & -0.41 & -0.37 \\
\hline $\begin{array}{l}\text { How often do members of your team disagree about the } \\
\text { delegation of tasks? }\end{array}$ & -0.62 & $\mathbf{0 . 9 5}$ & -0.45 & -0.70 \\
\hline $\begin{array}{l}\text { We had a target date when a draft of the project should be } \\
\text { done. }\end{array}$ & 0.59 & -0.41 & $\mathbf{0 . 8 8}$ & 0.43 \\
\hline $\begin{array}{l}\text { We had specific goals for when we want sub-tasks } \\
\text { completed. }\end{array}$ & 0.59 & -0.53 & $\mathbf{0 . 9 3}$ & 0.44 \\
\hline $\begin{array}{l}\text { My team had its own detailed schedule for finishing the } \\
\text { team project. }\end{array}$ & 0.70 & -0.35 & $\mathbf{0 . 9 2}$ & 0.37 \\
\hline $\begin{array}{l}\text { Members of my team used similar language when talking } \\
\text { about the team project. }\end{array}$ & 0.60 & -0.55 & 0.44 & $\mathbf{0 . 9 8}$ \\
\hline $\begin{array}{l}\text { Members of my team did not have trouble understanding } \\
\text { each other when working together on the team project. }\end{array}$ & 0.59 & -0.44 & 0.36 & $\mathbf{0 . 9 6}$ \\
\hline $\begin{array}{l}\text { Members of my team were always on the same page when } \\
\text { they talk about the team project. }\end{array}$ & 0.64 & -0.56 & 0.51 & $\mathbf{0 . 9 6}$ \\
\hline
\end{tabular}




\section{Appendix B - Correlation Matrix}

\begin{tabular}{|c|c|c|c|c|c|c|c|c|}
\hline & 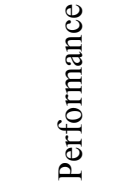 & 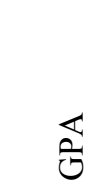 & $\stackrel{\mathscr{N}}{\sim}$ & $\underset{\stackrel{\Xi}{\Xi}}{\stackrel{0}{\ominus}}$ & 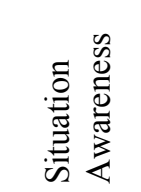 & 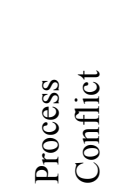 & $\begin{array}{l}\stackrel{\mathscr{U}}{\Xi} \\
\stackrel{\Xi}{\Xi} \\
\stackrel{\Xi}{\Xi}\end{array}$ & 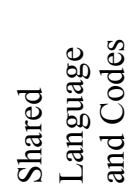 \\
\hline Performance & (na) & & & & & & & \\
\hline GPA & $-0.37 *$ & (na) & & & & & & \\
\hline Size & 0.29 & -0.11 & (na) & & & & & \\
\hline Tenure & -0.08 & 0.28 & -0.06 & (na) & & & & \\
\hline Situation Awareness & $0.46 * *$ & -0.07 & 0.13 & 0.01 & $(0.94)$ & & & \\
\hline Process Conflict & -0.15 & -0.12 & 0.01 & -0.16 & $-0.60 * * *$ & $(0.96)$ & & \\
\hline Deadlines & 0.19 & 0.07 & -0.01 & -0.09 & $0.69 * * *$ & $-0.47 * *$ & $(0.91)$ & \\
\hline $\begin{array}{l}\text { Shared Language and } \\
\text { Codes }\end{array}$ & 0.14 & -0.05 & -0.01 & 0.09 & $0.63 * * *$ & $-0.54 * *$ & $0.45^{*}$ & $(0.96)$ \\
\hline
\end{tabular}

